\title{
Technical Problematisation: A Democratic Way to Deal with Contested Projects?
}

\author{
YANNICK BARTHE, MORGAN MEYER and \\ GÖRAN SUNDQVIST
}

\begin{abstract}
A strong social and technical divide is particularly visible in the predominant understanding of technological innovation in modern societies. The field of Science and Technology Studies (STS) aims to overcome this divide, by focusing on the continuously entwined relationships between the social and the technical, that is, sociotechnical combinations. In this article, we argue that while it is reasonable to state that the social and the technical are entangled, it should be acknowledged that some issues are dealt with solutions that are more technical than others. A technical problematisation (the definition of an issue as a problem that is treated via a technical solution) is different to a social problematisation (the definition of an issue as a problem that is treated via a social solution) of the same issue. Our discussion is built upon examples from nuclear waste management, where the social-technical divide has been strong. However, more recently there has been a push for more democracy in technical decision making in this area, with much experimentation on public participation taking place. The only way these activities will successfully support such a democratising process is for them to be integrated into a renewed and explicitly acknowledged technical problematisation of proposed solutions.
\end{abstract}

Keywords: Technical problematisation, social-technical divide, sociotechnical combinations, nuclear waste management

\section{Introduction}

The conceptualisation of the relationship between the social and the technical has been a longstanding challenge for social scientists interested in technical innovation and social change. Today, most social scientists recognise the importance of technology for sustaining modern everyday life, including all the technical infrastructures that make it possible. With the help of technology, humans have

Morgan Meyer (corresponding author), CSI-i3, Mines ParisTech, PSL, CNRS, 60 bd Saint Michel, 75006 Paris, France. E-mail: morgan.meyer@mines-paristech.fr

Science, Technology \& Society (2021): 1-16

SAGE Publications Los Angeles/London/New Delhi/Singapore/Washington DC/Melbourne DOI: $10.1177 / 0971721821995584$ 
not only transformed society but also great parts of nature into what Beck in the 1980 s called 'the risk society'. Today, this is more often called 'the anthropocene': a planet transformed by human activities which are changing the atmosphere, the oceans, the use of land and the ecosystems (Latour, 2014). Moreover, the domestication and large-scale use of energy resources such as fossil and nuclear fuels have transformed these technologies from tools into actors. As the degree of carbon dioxide in the atmosphere increases and the clouds from Chernobyl and Fukushima contaminate the lives of plants, animals and human beings, the question about responsible actions and actors becomes crucial (cf. Callon, 1991, p. 142). Is it the combustion engines and power plants, or are we human beings responsible? According to Latour (1999, p. 190), it is in fact 'centuries too late' to talk about humans as independent of non-humans: the delegation of important practices to non-humans has gone much too far.

But how do social scientists relate to and attempt to grasp technological development? Contrary to what is said above, the most common way seems to be to completely ignore it. Social scientists are most of all interested in social problems and social institutions, taking technology for granted as an externality. Paradoxically, it seems to be anthropologists studying non-Western and less technologically developed societies who are interested in how humans and artefacts are entangled and together constitute a material culture, while sociologists studying human life in high-tech urbanised societies seem to be more interested in studies of 'pure' social relations. Yet, the apparent exemption is the field of Science and Technology Studies (STS), the branch of social science focusing on social and technical interactions as illustrated by Latour's argument above.

In this article, based on great sympathy for recent efforts in STS to transcend a strong technical and social divide by focusing on the entanglements of society and technology, thereby specifying sociotechnical combinations as the unit of analysis, we argue that this ambition has its limitations. One important limitation is that the goal of reaching beyond the social and the technical divide risks to neglect an important ambition in modern societies, that is, the pursuit of technical delegation allowing technical objects to do the job of humans. By focusing on what we call technical problematisation, we want to deepen our understanding of how technical delegation develops, and not least what makes technical problematisation and technical delegation a specific type of process that needs to be highlighted in the understanding of technological innovation. Due to a stronger focus on how controversial technical solutions are the result of specific ways of problematising an issue, social science can make a real contribution to improve both technical innovation and democratic processes.

In our discussion of different ways to understand social and technical interactions, we start from a separation between the social and the technical, with technology taking precedence over the social and the latter understood as the external context of the former. Then we discuss the attempt in STS to transcend a strong separation: the tendency being to see the social in the technical and the technical in the social, that is, the entanglement of the technical and the social, leading to 
sociotechnical combinations. However, we identify some frustration with this approach, which risks dismissing distinctions between what technology can do and what humans cannot do.

The identification and description of different understandings of the relationships between the technical and the social is not a purely academic exercise. On the contrary, these are also found in practical activities that aim to provide technical solutions in response to given problems. The distinction and relationships between the technical and the social are thus performative, as they produce a reality in accordance with these categorisations and as they have consequences for both technological innovation and democracy. Our discussion is built upon examples from nuclear waste management in Europe: the safety of nuclear waste infrastructures, the siting processes to determine future sites to dispose of the waste and the question of its retrievability/reversibility will help us to construct our argument (Bergmans, 2014). ${ }^{1}$

Nuclear power and nuclear waste provide a fertile terrain for our argument as they are characterised and managed by mobilising a strong divide between the technical and the social. The separation of the two realms has been constitutive of their governance since the splitting of the atom. The main reason for this separation is arguably the military legacy and its accompanying secrecy, as well as the strong delegation of responsibility to select groups of experts and the stifling of broad political debate on the issue (for further texts dealing with the issues of expertise, politics and inequalities in nuclear waste management, see, for example, Barke \& Jenkins-Smith, 1993; Chilvers \& Burgess, 2008; Elam et al., 2010). Boundaries are especially visible and policed: infrastructures for waste disposal are designed below the ground; access to plants and facilities is heavily regulated; and discussions usually happen in closed circles of experts, thereby excluding civil society and NGOs. However, the atomic bomb and nuclear power in general have, not least as a response to the secrecy involved, been one of the main objects of public protests and demonstrations in Western countries, demanding a more democratic handling of these issues. Due to this strong polarisation of the technical and the political, it has been a logical step for STS scholars to examine the interdependence of technical and political ambitions and how both aspects are entwined in the area of nuclear activities (Barthe, 2009; Hecht, 2009; Jasanoff \& Kim, 2009; Sundqvist, 2014).

Yet, we want to argue that, despite the entanglement of the social and the technical, it is important to characterise and understand social and technical problematisation as two different processes. A better understanding of technical problematisation might even hold the potential for increased democracy in radioactive waste management (this point will be developed in the conclusion). Rethinking the social and the technical in this way, we contend, also enhances our understanding of technical democracy (e.g., as introduced by Callon et al., 2009). Our argument, in other words, is that technical democracy is not only about opening up decisions to non-experts and giving them a voice, technology also needs to be problematised, debatable and - importantly - modifiable in order to do so. 


\section{From a Strong Social and Technical Divide to Sociotechnical Combinations}

Academic work in the social sciences has often focused on the technological determination of society, assuming that technology has an independent power to which society must adapt, what we call technological determinism. Another school of thought assumes that technology is nothing in itself but gains power through its social shaping, that is, social constructivism (MacKenzie \& Wajcman, 1999; Winner, 1986, p. 21). This contrast reinforces a strong distinction between the technical and the social, which prevents a deeper understanding of the nature of their relationship. The consequence of both approaches is that the social becomes empirically and analytically separated from the technical (see Akrich, 1995; Bijker, 1995).

Technological determinism not only implies the autonomous power of technology but also a specific kind of democracy that gives technology a specific location. Callon et al. (2009, pp. 35, 119-120) link technological determinism to what they call delegative democracy, which is based on two distinctions that are strongly maintained in Western societies: the division between lay people and specialists, and the division between citizens and their representatives. Thus, in addition to a strong divide between the technical and the political, delegative democracy means a double delegation: the delegation of political issues to elected representatives and the delegation of technical issues to specialists.

According to Callon, nuclear power has been instrumental in establishing the separation between the political and the technological, as well as the two distinctions and delegations mentioned above. The notion of an undifferentiated and ignorant public that is produced by delegative democracy 'is no less a by-product of nuclear power than is radioactive waste' (Callon, 2009, p. xiii).

However, technological determinism and delegative democracy hide the fact that there is ongoing engagement between the technical and the sociopolitical that they co-constitute - and respond to - each other. The success of an artefact is not a consequence of its internal and autonomously generated power; the relationships, aims, interests, developments and transformations should also be given attention to when explaining the success (Pinch \& Bijker, 1984, p. 406). Moreover, when problems arise-for example, when technical uncertainties and controversies leak from the technical domain into the political and public space, and become obvious and relevant to more people, such as global warming and a nuclear meltdowntechnical problems cannot be handled by technical experts alone. When this occurs, delegative democracy fails and the situation becomes 'hot' - scientific results must contend with public concerns. This situation is marked by controversy, that is, the absence of agreed knowledge, and the involvement of many actors (Callon, 1998, p. 260). In this situation, protecting old divides and a strong distinction between the technical and the political is a mistake that will only increase controversy. The only way to 'resolve' this situation is to take these controversies seriously and understand them as being part of new social arrangements - what has been called hybrid forums - that should be cultivated, not denied (Callon et al., 2009, pp. 18, 154).

One way to overcome a strong social and technical divide is to focus on the entanglements of the social and the technical and, even more so, to acknowledge 
that it is in fact impossible to separate them in practice. This entails the assumption of a sociotechnical combination sui generis, which then becomes the relevant object of study for social scientists analysing technological development. Such an approach is formulated by Bijker, beginning with a critical assessment of the strong separation of the technical and the social:

Purely social relations are to be found only in the imaginations of sociologists or among baboons, and purely technical relations are to be found only in the wilder reaches of science fiction. The technical is socially constructed, and the social is technically constructed... the sociotechnical is not to be treated merely as a combination of social and technical factors. It is sui generis. Instead of technical artifacts, our unit of analysis is now the 'sociotechnical ensemble'. (Bijker, 1995, pp. 273-274).

Law and Callon (1988, p. 285) propose the notion of a network as a 'metaphor for the interconnected heterogeneity that underlies sociotechnical engineering'. This metaphor is neutral with regard to both the technical and the social, and does not distinguish between them 'on a priori grounds' (p. 295). The social and the technical 'are jointly created in a single process... Context and content are similar in that both are social and technical' (p. 296, italics in the original). Moreover, we should remember the trap to be avoided: 'the notion that the technical and the social evolve as a result of separate processes and only subsequently interact' (p. 296). A similar understanding of the sociotechnical as sui generis, and not as an interaction between distinct and separated spheres, is given by the today widely supported notion of co-production (Jasanoff, 2004; Latour, 1993).

From what has been presented above, we join the majority of STS scholars in criticising technological determinism and delegative democracy. However, there is something about the power of technology, so important to technological determinism, that we need to further address. This power of technology must be acknowledged, but without seeing technology as autonomous. In order to develop this idea further, we first illustrate both the strong divide and the sociotechnical combinations by drawing on examples from nuclear waste management.

\section{The Technical and the Social in Nuclear Waste Management}

Our argument takes as its starting point the following empirical reality: today's discussions on how to dispose of nuclear waste take a strong social and technical divide for granted. Since the 1950s, when the negotiation of a global agreement on geological disposal started, safety has been the key issue (Sundqvist, 2002, pp. 65-66). Passive safety in relatively stable rock formations was considered the best solution to preventing leakage. The term 'passive safety', also sometimes called 'walk away safety' (Lynch et al., 1988), provides a good illustration of a vision of safety that is entirely delegated to technology and geology and that does away with a need for human actions, decisions or concerns. Today, geological disposal is 
an agreed global solution, and the task of achieving this in a safe way is generally considered to be one for technical experts.

In 2006, the European Council decided that the Euratom research should be focused on the implementation of deep geological disposal. A technology platform (Implementing Geological Disposal Technology Platform) was set up in order to demonstrate a common European view on waste disposal under the lead of Sweden and Finland, which are assessed as having the most developed waste programmes (Sundqvist \& Elam, 2010). To present geological disposal as a safe technological solution, built on host rock formation and specifically engineered barriers, and based on the work of geoscientists and engineers, means considering it as a question of scientific calculation. short, it involves the work of experts carried out in isolation and thereafter presented to politicians and the public as satisfactory (Elam et al., 2010). In 1977, Swedish engineers presented the now internationally famous KBS multi-barrier technical concept as an absolutely safe technology (KBS is short for KärnBränsleSäkerhet - Nuclear Fuel Safety) (Sundqvist, 2002, p. 79). When safety is discussed we thus often find a strong technical and social divide. The robustness of barriers, canisters and rocks is not only meant to prevent the leakage of waste and radioactivity but also, more generally, to prevent leakage between the technical and the social.

Actors responsible for national waste programmes and the European Union itself are of course well aware of the challenges involved in order to guarantee safety during the long time periods involved, including the many critical responses from citizens, social movements and some political parties. These controversies have led to a manifold of formats to involve citizens and foremost on the local level (Chilvers \& Burgess, 2008). One important sign of this is the European-funded research programmes focusing on governance issues and broadened participation in decision making concerning nuclear waste (Bergmans, 2014).

Nuclear waste management is one of the most controversial issues confronting nations who use nuclear power. From an STS perspective, the reason for this is obvious. The strong technical and social divide has its limitations and cannot deliver appropriate answers when the work of technical experts is questioned by politicians, the environmental movement and/or concerned publics. These groups often do not trust the figures presented by experts as proof of safety; they do not approve of the proposed sites that have been assessed as the best for hosting the waste; and they do not agree that geological disposal is the only and definitive solution or that one country should necessarily follow what has been done in other, more powerful and developed, nuclear nations. The standard response given by the 'technical community' to such concerns is that people are ignorant and should be better informed (this is called the 'information deficit model'; see Irwin \& Wynne, 1996). Usually, such a type of response only fuels controversy and can be seen as a technocratic failure to know the 'enemy'.

From an STS perspective, an important task is to show that this technocratic failure should be understood as a failure of technical experts to understand their own object of study and a failure to recognise the competences and interests of 
those who question their work. Technical work has its social assumptions and seemingly 'ignorant' publics are also knowledgeable and competent, and often have good reason to question the work of experts (Epstein, 1995; Wynne, 1996, 2001).

Nuclear waste management also provides rich examples of how the social influences the technical. The calculation of safety is always based on a number of factors: the norms and criteria constituting the requirements on the basis of which safety is assessed (how much safety do we need?), descriptions of the barriers, and the possible processes and events that might be a threat to the integrity of a repository. Scenarios are chosen on the basis of their likelihood, as being the worst case, or on the basis of other assumptions that are assessed as being of interest to society. Finally, they are considered in relation to the safety requirements established by the politicians and state bureaucrats responsible for the issue (Elam et al., 2010, p. 200). STS scholars have no problem understanding the picking and choosing of these criteria and factors - deemed as most relevant - as choices deeply based on societal assumptions about what safety is, and for whom and to what degree it must be established. More seldom is this social influence recognised in public discussions, or acknowledged by responsible technical experts. Often there is a strong focus on safety as being a purely technical issue.

Siting is often presented as a phase of implementation where social acceptance must be sought, because the many examples of technocratic failure have proved that acceptance is not a given. The nuclear industry and agencies have attempted to restore and reframe siting programmes to allow more space for input from local inhabitants and interest groups - 'opening up the selection process'. New 'political tools' such as dialogue meetings and public hearings have been developed to increase acceptance by permitting a certain degree of local influence. However, we should note two different strategies used by the technical community to deal with these new tools. The first, as evident in the Czech Republic, is to refuse to back down on the expert assessments made in advance. This leads to public dialogues becoming 'empty exercises' that do not develop acceptance but only frustration among the participants, leading to technocratic failure once again (Konopásek et al., 2014). Another strategy can be seen in the case of Sweden, where experts were willing to adapt bedrock preconditions based on what was socially acceptable. The result was a sociotechnical combination, with the search for bedrock addressing both technical and social requirements. However, this particular hybrid was not deliberately discussed as such, but was determined by experts who assessed how to achieve acceptance from local inhabitants behind closed doors (Sundqvist, 2014).

The reversibility and retrievability of nuclear waste is an issue that is most obviously of a sociotechnical nature. The social aspects and assumptions involved in reversibility and retrievability can easily be identified. The plans for reversibility and retrievability are to a great extent connected to the assumed behaviour of future generations and the kind of society we expect they will live in, both in relation to technological development and social behaviour, and whether we expect utopias or dystopias. Generally, a focus on reversibility and retrievability could be seen as 
a corrective to the high levels of technocratic self-esteem involved in presenting safe and definitive solutions, opening them up to promote an attitude of humility or open-mindedness towards the future (Jasanoff, 2003).

An analysis of the safety, siting and retrievability/reversibility of nuclear waste reveals the limitations of a model in which there is a strong divide between the technical and the social. These topics - which are of great relevance to radioactive waste management - are thus better understood in terms of sociotechnical combinations. While this assessment is in line with standard STS approaches, we want to emphasise that analysing technology as essentially involving sociotechnical combinations also has some limitations. The processes of delegation, the distinctions between human and technological capacities, the 'divisions of labour' between technologies and social processes, as well as the nature and fragility of sociotechnical combinations are at risk of being overlooked from this perspective. Thus, below we offer a way to move beyond these limitations while carefully avoiding any technological determinism or essentialism.

\section{Technical Problematisation}

An important part of being able to understand the differences between current and potential sociotechnical combinations is to see them as a result of a process of problematisation. The notion of 'problematisation' has a long and rich history in the social sciences. We must mention, of course, the work of Michel Foucault and the work of social science scholars inspired by actor-network theory (Callon, 1980, 1986). The notion has been used and defined in different, sometimes contradictory, ways across various disciplines and by various authors. Our aim is to adopt a simple definition: problematisation is the process of defining what is a problem in a given situation, identifying the causes of this problem and proposing ways to resolve it. The notion of problematisation is somewhat similar to that of 'framing', which is used in the analysis of the construction of public problems and social movements (Benford \& Snow, 2000; Entman, 1993). However, we prefer to use problematisation as it puts more emphasis on dynamic social processes and thus avoids the sometimes static nature of the concept of a 'frame', which is too often associated with reified ideological patterns and the media. Our use of the term problematisation also shapes our reading of what 'problems' are. A 'problem', in this article, denotes a situation that needs to be dealt with and not necessarily something that is valued as being 'bad', 'harmful' or 'difficult'. We are not looking at the supposed essence a problem, but in a more temporal and dynamic manner, at the ways in which a problem is dealt with, and how it unleashes a variety of processes and strategies in doing so.

Using the above definition, it is important to keep in mind that the process of problematisation implies not only the general formulation of a problem but also the identification of the ways in which to address it and, consequently, of the most legitimate actors and spaces to do so. In other words, problematising an issue not only entails determining what it is, but also determining who should address it, in 
what way and with which means. Problematisation is a social activity that combines the processes of qualification and of setting an issue within a space of reflection and specific treatment, or, as Foucault (1990, p. 670) put it, 'constitute it as an object of thought (whether in the form of moral reflection, scientific knowledge, political analysis, etc.)'.

Usually, when faced with a controversy, actors propose different problematisations of the same situation. In other words, they do not define what is problematic in the situation, or how to deal with the problem, in the same way. For example, in a conflict situation concerning geological disposal of nuclear waste, at least two problematisations of the situation usually clash. For those undertaking the project, the main concern is the public — which is opposed to the project — not the project itself. Thus, it is the public that needs to be questioned, its 'emotional', 'irrational' response needs to be analysed, understood and rectified. In this case, what must be changed is the 'environment' or context of the project, but not the project itself. The technological aspects of the project are seen and presented as the 'right' solution, which is neutral and robust - as opposed to the subjectivity of the public. For the opponents of the project it is, on the contrary, the project itself that poses the main dilemma - questions and discussions thus need to focus on the project. From this perspective, the project is not considered to be the 'right' solution or non-negotiable. Here, the technological choices, limitations and alternatives come to the fore. Thus, at least two ways of addressing a technological project can be empirically observed. And with this article we want to provide a theoretical framework to comprehend these two very different types of problematisation: one that might be called social problematisation and the other technical problematisation. While this distinction is, of course, a theoretical and analytical one, it is important to keep in mind that it is thoroughly grounded in empirical realities. It is the ways in which actors deal 'on the ground' in the nuclear world with specific issues, and the kinds of solutions they imagine and mobilise that call, in our view, for the necessity of drawing this distinction.

Technical problematisation means that the problematic situation will lead to a change to the initial technical project. Here the problematic situation creates a new constraint that will be integrated into the technical project. This is a new challenge, a new trial that is likely to act as a catalyst to innovation. For example, the concept of geological disposal is the result of a technical problematisation. The main idea is to build a sort of geological 'safe' since the problem cannot be socially solved: there is incertitude of how future generations will deal with nuclear waste as much as there are potential wars and political changes that cannot be foreseen. Other examples of technical problematisation, outside of the field of nuclear waste management, are door closers that replace human actions (humans needing to close doors behind then) by a technological device (Latour \& Johnson, 1988) and safety belts that protect car drivers. The latter two devices are good examples of technical problematisation for they deal with everyday issues by trying to solve them through technical artefacts. That is why we should not consider technical problematisation as only based upon the selection of the 'technical' characteristics of a problem 
(and thereby ironing out its other dimensions, an argument often raised by certain critics of technocracy who point out the narrow-mindedness of technicians). This type of problematisation can be seen as a process of translation

which enables the different dimensions of a problem to be constituted-whether they are formulated in moral, economic or political terms - as so many technical challenges that engineers and scientists will strive to meet. [...] In this perspective, we can see that technically problematizing an issue is not suggesting that it is only a technical issue; rather, it is asserting that the issue is technically solvable. (Barthe, 2009, pp. 943-944, italics in the original)

In contrast, social problematisation means that for instance opposition to a project is seen as a problem in itself (as autonomous and completely independent of the characteristics of the project). As such, it should - and therefore a priori could - be treated with a solution other than a technical one, that is, a solution that does not require a modification of the project itself. This sort of problematisation often leads actors to work on issues related to information, communication or participation. For example, the first manifestations against nuclear energy from the 1950s onwards have been interpreted by experts from the WHO as problems with mental health and as essentially being based upon a lack of scientific culture that needed to be corrected with more information (OMS, 1958). Another example is the emphasis put on risk communication in Japan after the Fukushima accident, with the nuclear industry trying to rebuild 'support' and 'trust' for nuclear power (Kimura, 2016). The idea of a social problematisation is to use instruments that will change the project's environment, making it less hostile. This type of problematisation often entails the implicit idea that conflict is the result of a misunderstanding, and that such conflict can be treated politically. Social scientists, psychologists or specialists of risk communication often contribute to this form of problematisation, overemphasising the procedural aspects of 'dialogue' and participation, and paying less attention to the 'technical' content of the debate (Sundqvist, 2014).

By using the term 'technical problematisation' and distinguishing it from 'social problematisation', do we not eventually fall back into a divide that much academic work has tried to undo? Our answer is no, as this distinction concerns an empirical and heuristic division of two processes, but not an essentialist conception of the technical and the social. We are concerned with how issues are understood and discussed, the various approaches to technical or social solutions and different kinds of problematisations; in other words, we defend a methodological and practical standpoint, not an essentialist and ontological paradigm. We hold that differentiating between processes of technical and social problematisation is empirically legitimate and rigorous, and that it is theoretically insightful. We hold that there is a need to resist the temptation to examine and celebrate the entanglements and co-productions between technical and social processes but to be attentive to differences and separations. Our stance is thus explicitly not to hold that hybrid worlds are more effective or more democratic and that there needs to be more exchange, 
better integration and so forth. STS has already done the job of showing and calling out for that on many occasions.

By making this distinction, we acknowledge the fact that actors constantly seek to distinguish worlds to 'purify' what is 'technical' and what is 'social'. It is unrealistic, in other words, to expect everyone to problematise the technical and the social in the way STS scholars do. STS scholars indeed have usually no problem acknowledging the existence of such purifying ambitions, recognising that the work of purification goes hand in hand with the work of hybridisation, and that purified 'social' and 'technical' objects, as representations of complex network associations, could be both necessary and useful since they make things simpler and the world more manageable (Konopásek et al., 2008; Latour, 1993).

This implies being sensitive to the way issues are problematised, framed and organised. When analysing nuclear waste management, this means being attentive to how the technical solution - such as geological disposal-has become 'the solution', often understood as a definitive and inevitable solution (a pure technical solution) that should 'merely' be implemented. Geological disposal entails its own social assumptions - evaluations - that could be summarised as 'bedrock is more reliable than society'. But why is technical problematisation being seen as more reliable and robust? And why, more generally, does one type of problematisation outweigh the other in some cases?

We can make an assumption about these questions. It seems clear that the more flexible a technical project appears, the greater the chances of a technical problematisation being imposed. A flexible project can, in fact, adapt itself to a 'hostile' environment. Conversely, if the technical project itself is not seen as adaptable, it cannot be used as a resource to solve the conflict. The consequence, which should be noted, is that conflicts in these cases do not lead to the creation of a dynamic form of technical innovation but, on the contrary, to a problematisation of the social environment-what we call social problematisation.

So, for a technical problematisation to develop, it is important that there is no technological lock-in, that the project is not a prisoner of history and that its trajectory is not forever dependent on a given path. If this is not the case, participatory procedures or public debate will merely feed the social problematisation but not the technical one: a divide is then created between 'definitive solutions' and people participating in sterile procedures merely to gain acceptance for these solutions. For innovation and democracy to be meaningful, however, the technical object must be open to change (Barthe et al., 2020).

The strong focus on safety that we find in nuclear waste management is interesting in this respect. Wynne (2001) has argued that framing environmental and health issues as questions of safety and risk - common today in research as well as in public discussions - omits knowledge that does not suit this framing. The result is a strong expert focus that does not acknowledge its own limitations and also considers others to be ignorant. Questions such as 'why do we produce radioactive waste?' and 'why is geological disposal the first choice?' are deemed irrelevant by decision makers and advocates of the project. When such expert framings, focused on risks 
and safety, meet the understanding of the issue held by lay people, misrepresentation occurs and this often leads to a clash between two different problematisations.

The problem of siting, as already suggested, can be seen as a social problematisation of the waste issue that arises as a consequence of a narrow technical framing of it. Siting becomes an object of concern when the expert solution is not readily accepted by local inhabitants. Too often this leads the pendulum to swing, with 'pure' social questions coming into focus and public opinion, lay people's concerns, participatory approaches and all kinds of communication activities becoming fundamental, while the technical object - the design of the repository and its chosen bedrock site - is put into the background and not at all problematised. Of course, social problematisation can originate from both proponents and opponents of the project and can address important and legitimate concerns. However, this does not contribute to what has been called 'technical democracy'. To encompass this, social problematisations must be temporally situated and seen as a direct consequence and as a possible solution to the inherent limits of technical problematisation. It is important to note that social problematisation not only suggests that there is another way to deal with a problem but also transforms the problem: as a consequence of a more 'democratic' approach, the problem becomes less local and more national, involving several different locations. In so doing, social problematisation also evaluates, qualifies and undoes technical problematisation (i.e., as not sufficiently 'democratic', 'public', 'transparent', 'open', etc.).

For instance, the issue of retrievability and reversibility tells us that taking reversibility seriously means holding technical alternatives open, that is, to treat the technical object as negotiable, implying a continuous problematisation of the technical. This is the case in France where, although the technology of geological disposal is still used, at least some technical aspects of geological disposal have been questioned and now take into account the requirement of reversibility (ramps, mobility of canisters, materials used, accessibility of site, etc.) (Barthe, 2009; Barthe et al., 2020). A full-blown technical democracy requires that both the design of the technical object - that is, geological disposal — and the instruments used for social problematisations - such as public dialogues - are treated as negotiable. The issue of retrievability and reversibility has the potential to be developed in this way. If not, the two realms of problematisation will simply mirror the technical and social divide.

\section{Conclusion}

Let us now summarise the main lessons learned from the above discussion, and how a focus on problematisation (and, above all, technical problematisation) could help enhance technical democracy, for instance in European nuclear waste management. We began by underlining a paradox in nuclear waste management. On the one hand, many actors agree that a more democratic way of dealing with nuclear waste is required. Often this is interpreted as allowing public debate, communicating with stakeholders and introducing consultation procedures. All of these 
tools are supposed to open the technical choices to a discussion so that they may be accepted more readily. However, the paradox is that in many cases these technical choices or solutions are black boxed and their content is no longer debatable. Here, the tools of public debate are not seen as assisting the technical decision-making process. The technical solutions and choices are not debatable or modifiable. More importantly, some actors do not want to open these decisions to public scrutiny, and seek to guard them against any attempt to question them.

We have attempted to gain a better understanding of this paradox, and also suggested a way to move beyond it. This does not mean engaging in what social scientists are usually expected to do. The contribution of the social sciences is often seen as a way to illuminate the 'social aspects' of controversies, that is, to study the public's perceptions and responses, its level of acceptance, its beliefs, its interests, its in- and exclusions, and so on. As has been shown above, this conception of the contribution of the social sciences is directly related to a strong divide between social and technical aspects. Examples concerned with critical issues in radioactive waste management revealed practices that are often based on a strong social and technical divide.

We have seen that this divide comes in various guises. Safety is delegated to technologies, engineered barriers and the properties of rock, and it is seen as requiring only 'passive' processes. The process of siting is temporally divided into a technical and geological phase, and a subsequent phase of public and political 'acceptability'. Reversibility and retrievability is often qualified as a purely 'social' demand, at odds with the definitive solutions of experts.

If the technical is seen as completely separated from the social, it is more difficult for the former to be discussed and challenged by actors other than the experts themselves. This is why, in this case, public participation is focused on improving the 'context' of geological disposal projects but not on the technical aspects themselves. Here, the debate concerns aspects of nuclear management that might be important for people but that remain on the 'periphery' of the technical decisionmaking process. Of course, the implementation of public participation procedures is a way to improve the democratisation of nuclear waste management. However, if the technical decisions are not open to discussion, it cannot be said that real change or any real development of technical democracy has occurred. Communicating about and discussing the impact of technological choices should not be mistaken for participation in the decision-making process that led to these choices.

Thus, the question is: What conditions are required to develop technical democracy? First and foremost, a better understanding of the content and nature of the technical solutions is required. This means demonstrating that all the 'technical' solutions proposed in this field are sociotechnical combinations that result from what we have called a process of 'technical problematisation', that is, the transformation of many problems into technical features. This process of technical problematisation is actually at the heart of all innovation processes and the way we describe and explain technical development. Technical problematisation can also be seen as a very efficient way to deal with controversies, as it offers a way to address external 
criticism of projects, of whatever kind. This process of problematisation takes into account external constraints and leads to sustainable and viable technical projects.

Our main conclusion is that the only way to move beyond the paradox mentioned above is to be open to this process of technical problematisation. This means that the 'technical project' has to be understood as flexible and negotiable, so as to be able to deal with potential constraints of various kinds. It also means that public participation has to be seen as a tool that feeds this technical problematisation. From our point of view, this is the only way to achieve technical democracy, be it in nuclear waste management or in other fields. To focus on sociotechnical combinations without the qualification of the possibilities for technical problematisation is not a solution and could, in the worst case, confuse the understanding, implying that technical solutions are nothing special at all. However, sociotechnical combinations could be a good point of departure for conducting studies on technical problematisation.

We do not want to imply here that technical problematisation is an easy process, nor that it provides a silver bullet to solve technological controversies and guarantee democratic processes. Quite the contrary, technical problematisation is perhaps even more complex, as it takes time and efforts to get to grips with technological details. However, both empirically and theoretically, it allows us to better comprehend technological change and how it is open - or not - to democratic procedures. It also allows us to move beyond either/or positions and conflicts (i.e., being either for or against genetically modified organisms (GMOs), nuclear power, shale gas, etc.) by putting different questions on the agenda: What kinds of technology do we want or need? What potentials, limits, effects, flexibilities and alternatives do technologies have? What kinds of expertise, design, maintenance, funding and infrastructures do they require? And, importantly, who is able to raise and frame these questions and have a say in these discussions?

\section{DECLARATION OF CONFLICTING INTERESTS}

The authors declared no potential conflicts of interest with respect to the research, authorship and/or publication of this article.

\section{FUNDING}

This work was supported by the Seventh Framework Programme [Grant number 269906].

\section{NOTE}

1. The examples given in this article are taken from a EU-funded project, called InSOTEC (International Socio-Technical Challenges for Implementing Geological Disposal), which the authors took part in (2011-2014). The project was based on fourteen country reports, which were followed up by fifteen cases studies focusing on critical issues of importance in the majority of the fourteen nations, such as safety, siting and retreivability/reversibility (Bergmans, 2014). One 
important aim of the project was a comparative optics to study why some things are taken for granted in one country but not in others? Or in the framing of this article: Why does one type of problematisation outweigh the other in some cases?

\section{REFERENCES}

Akrich, M. (1995). User representations: Practices, methods and sociology. In A. Rip, T. J. Misa, \& J. Schot (Eds.), Managing technology in society: The approach of constructive technology assessment (pp. 167-184). Pinter.

Barke, R. P., \& Jenkins-Smith, H. C. (1993). Politics and scientific expertise: Scientists, risk perception, and nuclear waste policy. Risk Analysis, 13(4), 425-439.

Barthe, Y. (2009). Framing nuclear waste as a political issue in France. Journal of Risk Research, 12(7-8), 941-954.

Barthe, Y., Elam, M. \& Sundqvist, G. (2020). Technological fix or divisible object of collective concern? Histories of conflict over the geological disposal of nuclear waste in Sweden and France. Science as Culture, 29(2), 196-218.

Benford, R. D., \& Snow, D. A. (2000). Framing processes and social movements: An overview and assessment. Annual Review of Sociology, 26, 611-639.

Bergmans, A. (2014). International socio-technical challenges for implementing geological disposal (Project Final Report FP7, SP5-Euratom). https://www.insotec.eu/

Bijker, W. E. (1995). Of bicycles, bakelites, and bulbs: Toward a theory of sociotechnical change. The MIT Press.

Callon, M. (1980). Struggles and negotiations to define what is problematic and what is not: The sociologic of translation. In K. Knorr, R. Krohn, \& R. Whitley (Eds.), The social process of scientific investigation (pp. 197-219). Dordrecht.

Callon, M. (1986). Some elements of a sociology of translation: Domestication of the scallops and the fishermen of St Brieuc Bay. In J. Law (Ed.), Power, action and belief: A new sociology of knowledge? (pp. 196-223). Routledge.

Callon, M. (1991). Techno-economic networks and irreversibility. In J. Law (Ed.), A sociology of monsters: Essays on power, technology and domination (pp. 132-161). Routledge.

Callon, M. (1998). An essay on framing and overflowing: Economic externalities revisited by sociology. In M. Callon (Ed.), The laws of the markets (pp. 244-269). Blackwell Publishers.

Callon, M. (2009). Foreword. In G. Hecht (Ed.), The radiance of France: Nuclear power and national identity after World War II (pp. xi-xxiii). The MIT Press.

Callon, M., Lascoumes, P., \& Barthe, Y. (2009). Acting in an uncertain world: An essay on technical democracy. The MIT Press.

Chilvers, J., \& Burgess, J. (2008). Power relations: The politics of risk and procedure in nuclear waste governance. Environment \& Planning A, 40(8), 1881-1900.

Elam, M., Soneryd, L., \& Sundqvist, G. (2010). Demonstrating safety-Validating new build: The enduring template of Swedish nuclear waste management. Journal of Integrative Environmental Sciences, 7(3), 197-210.

Entman, R. M. (1993). Framing: Toward clarification of a fractured paradigm. Journal of Communication, $43(4), 51-58$.

Epstein, S. (1995). The construction of lay expertise: AIDS activism and the forging of credibility in the reform of clinical trials. Science, Technology \& Human Values, 20(4), 408-437.

Foucault, M. (1990). The history of sexuality, Vol. 2: The use of pleasure. Vintage.

Hecht, G. (2009). The radiance of France: Nuclear power and national identity after World War II. The MIT Press.

Irwin, A., \& Wynne, B. (Eds.). (1996). Misunderstanding science? The public reconstruction of science and technology. Cambridge University Press.

Jasanoff, S. (2003). Technologies of humility: Citizen participation in governing science. Minerva, 41(3), 223-244. 
Jasanoff, S. (2004). States of knowledge: The co-production of science and social order. Routledge.

Jasanoff, S., \& Kim, S. H. (2009). Containing the atom: Sociotechnical imaginaries and nuclear power in the United States and South Korea. Minerva, 47, 119-146.

Kimura, A. H. (2016). Risk communication under post-feminism: Analysis of risk communication programmes after the Fukushima nuclear accident. Science, Technology and Society, 21(1), 24-41.

Konopásek, Z., Soneryd, L., \& Svačina, K. (2014). Czech dialogues by Swedish design (Working paper of the InSOTEC project [WP 2]). InSOTEC.

Konopásek, Z., Stöckelová, T., \& Zamykalová, L. (2008). Making pure science and pure politics: On the expertise of bypass and the bypass of expertise. Science, Technology, \& Human Values, 33(4), 529-553.

Latour, B. (1993). We have never been modern. Harvard University Press.

Latour, B. (1999). Pandora's hope: Essays on the reality of science studies. Harvard University Press.

Latour, B. (2014). Agency at the time of the anthropocene. New Literary History, 45(1), 1-18.

Latour, B., \& Johnson, J. (1988). Mixing humans and non-humans together: The sociology of a doorcloser. Social Problems, 35(3), 298-310.

Law, J., \& Callon, M. (1988). Engineering and sociology in a military aircraft project: A network analysis of technical change. Social Problems, 35(3), 284-297.

MacKenzie, D., \& Wajcman, J. (Eds.). (1999). The social shaping of technology (2nd ed.). Open University Press.

Organisation Mondiale de la Santé (OMS). (1958). Questions de santé mentale que pose l'utilisation de l'énergie atomique à des fins pacifiques [Mental health issues raised by the peaceful use of atomic energy] (Vol. 151). Organisation mondiale de la santé.

Pinch, T. J., \& Bijker, W. E. (1984). The social construction of facts and artefacts: Or how the sociology of science and the sociology of technology might benefit each other. Social Studies of Science, 14(3), 399-441.

Sundqvist, G. (2002). The bedrock of opinion: Science, technology and society in the siting of high-level nuclear waste. Kluwer Academic Publishers.

Sundqvist, G. (2014). 'Heating up' or 'cooling down'? Analysing and performing broadened participation in technoscientific conflicts. Environment \& Planning A, 46(9), 2065-2079.

Sundqvist, G., \& Elam, M. (2010). Public involvement designed to circumvent public concern? The 'participatory turn' in European nuclear activities. Risk, Hazards and Crisis in Public Policy, 1(4), 203-229.

Winner, L. (1986). The whale and the reactor: A search for limits in an age of high technology. Chicago University Press.

Wynne, B. (1996) May the sheep safely graze? A reflexive view of the expert-lay knowledge divide. In S. Lash, B. Szerszynski, \& B. Wynne (Eds.), Risk, environment \& modernity: Towards a new ecology (pp. 44-83). SAGE Publications.

Wynne, B. (2001). Creating public alienation: Expert cultures of risk and ethics on GMOs. Science as Culture, 10(4), 445-481. 